Edith Cowan University

Research Online

ECU Publications 2013

$1-1-2013$

\title{
Toward a phen(omen)ology of the seasons: The emergence of the Indigenous Weather Knowledge Project (IWKP)
}

John Charles Ryan

Edith Cowan University

Follow this and additional works at: https://ro.ecu.edu.au/ecuworks2013

Part of the Climate Commons, and the Critical and Cultural Studies Commons

This is an Author's Accepted Manuscript of: Ryan, J.C. (2013). Toward a phen(omen)ology of the seasons: The emergence of the Indigenous Weather Knowledge Project (IWKP). Environment, Space, Place, 5(1), 103-131.

Available here

This Journal Article is posted at Research Online.

https://ro.ecu.edu.au/ecuworks2013/634 


\title{
Environment, Space, Place
}

Special Issue on 'The Seasons'

Article Submission Title Page

\author{
John Charles Ryan \\ Edith Cowan University \\ john.ryan@ecu.edu.au
}

0893706454

\section{Biography}

John Charles Ryan is a poet, environmental writer, and amateur naturalist. He is currently a Postdoctoral Research Fellow in the School of Communications and Arts at Edith Cowan University in Perth, Western Australia. His poetry appears in Two With Nature with the botanical artwork of Ellen Hickman (Fremantle Press, 2012). In 2013, his performance poetry will be included in the collection Fremantle Poets 3 (Fremantle Press). He is also the author of the ecophilosophical and ecocritical monographs Green Sense (TrueHeart, 2012) and Unbraided Lines (CG Publishers, forthcoming, 2013). 


\title{
Toward a phen(omen)ology of the seasons: The emergence of the Indigenous Weather Knowledge Project (IWKP)
}

\begin{abstract}
Since European settlement, the Western calendar has insufficiently accounted for the seasonal nuances and multiple temporalities of Australia. Beginning with Tim Entwistle's recent proposal to revise the four-season Australian norm, this article traces the emergence of the Western calendar in Europe and its institutionalization 'Down Under'. With its emphasis on land-based calendars, the Indigenous Weather Knowledge Project (IWKP) is a partnership between Aboriginal communities and the Bureau of Meteorology aimed at preserving and promoting knowledge of the endemic seasons of Australian regions. As the most recent addition to the IWKP, the six-season Nyoongar calendar of the South-West of Western Australia is based on meteorological conditions (ecological time), such as wind directions and temperatures, but also on the procurement of food, maintenance of cultural knowledge, and performance of ceremonies (structural time). Through the fusion of phenomenological (experiential, sensory, place-based, actual) and phenological (cognitive, visual, enumerative, digital) approaches, the endemic seasons of Australia can be appreciated in their depth and extent.
\end{abstract}




\section{Introduction: Revising the Australian seasons}

In a recent article in Australian Geographic, Tim Entwistle, Director of Conservation at Kew Gardens and former Director of the Sydney Botanic Gardens Trust, proposes a five-season model for Australia. Entwistle's schema includes a weightier four-month summer (December-March), a slenderer two-month autumn (April-May), and a compressed twomonth winter (June-July). Revising and reassigning the antipodean seasons, he divides spring into a two-month "sprinter" (August-September) and two-month "sprummer" (OctoberNovember). Entwistle's revisionist five-season thinking unmistakably emphasizes the Australian summer, comprising one-third of the calendar year in his schema. Additionally, spring (as the neologism "sprinter") begins in August — one month earlier than its four-season counterpart - to correspond to the flowering of native plants in many parts of the country. Critical of the European temporal grid, Entwistle regards seasons as "cultural constructs reminding us that there are cyclic changes in the environment" (quoted in Duncan 2011). Judging from his revisionist proposal, the usual constructs-spring, summer, autumn, winter-are unsatisfactory 'Down Under'.

In Entwistle's view, the Australian seasons require reconsideration, optimistically leading to new modes of seasonal awareness. On the surface, five seasons more sensibly accommodate the natural cycles of the Australian landscape. His ecologically inspired calendar, in part, adjusts its demarcations to the chief flowering time of Australian native flora as a whole. However, while I recognize that Entwistle's five-season tender is praiseworthy, any template for generalizing the Australian seasons inevitably becomes ensnared in the mode of cultural construction that it seeks to overcome. In its reconfiguring and compartmentalizing of the cyclical progression of time, Entwistle's model reproduces the ineluctable weaknesses of a single seasonal paradigm for a land mass as vast and diverse as Australia. The cultural construction of the seasons - exemplified by the Gregorian or Christian calendar now used by nearly all Western countries (Aveni 1990, 116-117)_implies a singular and monologic rendering of seasonality, largely dislocated from the ecological nuances of regions.

Whether four or five in number, an Australian seasonal standard needs to be thoughtfully and continually counterbalanced by local knowledge of the seasons, encapsulated within Indigenous ecological calendars. While an incomplete formulation of Australian seasonal plurality, the five-season model's opening to regional land-based calendars offers a promising way forward and a basis for deeper understanding of the 
seasons. In short, broadly based models of seasonality —including Entwistle's — can be enhanced through sustained reference to the tacit embodied knowledge encoded within indigenous calendars. Hence, in response to Entwistle, a dialogic perspective on the seasons considers multiple places, scales, temporalities, ecologies, bodies, and cultural traditions. As a counter-example to the five-season proposal, the Indigenous Weather Knowledge Project (IWKP) offers a means for balancing any single, fixed system. The project aims to consolidate the seasonal knowledge of Aboriginal cultures in consultation with their elders (Australian Bureau of Meteorology 2012a). One of the practical outcomes of the IWKP is the digital documentation of indigenous calendars on the project's website. Hence, the IWKP is poised to educate the public through open-access information about land-based or endemic seasons.

The purpose of this article is to trace the backstory to Entwistle's call to reformulate the Australian seasons. In sketching the context broadly, I begin with the origin of the Gregorian construct, alluding to its importation to Australia as part of the processes of colonization since the $18^{\text {th }}$ century. Here, I argue that the singular model of the four seasons displaced (and potentially still displaces where traditional knowledge networks are threatened) the multiple modes of season-reckoning in Australia. I then go on to consider the twin notions of endemic seasonality and indigenous calendars through historical reflection on the six-season Nyoongar calendar (Bates 1985, Moore 1884/1978, Ryan 2012a, Bindon and Walley 1992). The Nyoongar are the Aboriginal people of the South-West corner of Western Australia (Green 1984, Van den Berg 2002, South West Aboriginal Land \& Sea Council 2009). After the case study of the Nyoongar calendar and its embodied, phenomenological aspects, I proceed to a brief analysis of the IWKP.

Throughout my longitudinal discussion of the Australian seasons-from longstanding Indigenous traditions, to the Gregorian import, and to contemporary modes of Australian season-telling, represented by the IWKP-I propose and develop the portmanteau 'phen(omen)ology' in relation to the seasons. I argue that the IWKP is best conceived of as an online phenological template that gives actual human phenomenological exploration of the seasons a reference point for contemporary Australians interested in getting to know the endemic seasonalities of their places. Both phenology and phenomenology are essential to the process of grasping the meaning of endemic seasonality in Australia and to learning to live with the seasons more consciously and concertedly. 


\section{Seasons of things: A phenomenology of dwelling with/in}

Before addressing the backstory to Entwistle's five-season call, I set out my philosophical position on the seasons through the phen(omen)ology concept. I ask: How should we rethink the four Australian seasons in a manner that is sensitive to Australian places and cultures? How can individuals learn about the seasonal specificities of where they live in connection to national standards of seasonality, whether four or five? And, how can settler culture in Australia - steeped in four-season perception-begin to appreciate and hopefully "dwell" with and in the endemic seasonalities of regions, as described by Aboriginal cultures? As suggested in the previous section, the incorporation of land-based seasonal knowledge into Australian culture through indigenous calendars is optimally approached phenomenologically and phenologically. The former occurs as an individual's experience of the seasons through sight, hearing, touch, taste, and olfaction: as physical sensations registered in the body sensorium. The latter refers to cognitive awareness of the progression of ecological events in time linked to plants, animals, the wind, constellations, and other biotic and abiotic phenomena. To begin with, phenomenological engagement centralizes immediate physical knowledge of the endemic seasons of a place: seeing, tasting, feeling, touching, and smelling the seasons, in their tangible manifestations, as they unfold. In adumbrating a phenomenology, Martin Heidegger's notions of dwelling (1971, 143-159) and "the thing" (1971, 163-180), in conjunction with Maurice Merleau-Ponty's embodied phenomenology (2012), are crucial frameworks. Recent theoretical developments in phenomenological geography (Bender 2002, Tilley 1994, 2010) and phenomenological approaches to literary and cultural studies through the concept of "embodied temporality" (Ryan 2012) also provide important conceptual positions.

Here, it is crucial to recognize that indigenous ecological calendars, such as those of the Nyoongar and Yawaru of Western Australia, are lived calendars. The sensory cues of ecological calendars are intrinsically connected to intimate seasonal knowledge. When navigated phenomenologically in the environment, these cues-e.g., the ripening of the cocky apple and its sensory materializations through pungent smell, sweet taste, and pleasing image - signal the changing of the seasons integrated to human bodily resonances. Thus, for Australian settler society, a return to endemic seasonality entails corporeal participation in places of dwelling. My phenomenological call is heightened by the fact that ecological indicators of seasonal onset and transition vary annually according to manifold factors, such as rainfall, made even more irregular by the seasonal disruption associated with climate 
change (Steffen et al. 2009, 68, CSIRO 2011). To state the need differently, in order to appreciate endemic calendars, one must recognize their indications physically and immanently; a phenomenology of the seasons is therefore bodily, multi-sensory, and integrative of nature and culture.

A phenomenology of the seasons attends to the "things" of nature (animals, plants, rain, wind) which, in their sensuous being, announce the seasons and their passage. Heidegger's 'dwelling' is a key concept, developed in his essay "Building Dwelling Thinking" (1971, 143-159). Through human place-dwelling, the presencing of the seasons comes forth and registers sensorially. For Heidegger, dwelling is the necessary quality of being. In examining the notion of dwelling in relation to Heidegger's articulation of "the thing" (1971, 163-180), a philosophy of the seasons situates the vital things of nature - in their particular modes of being as sensorially manifested — before the fixed, mathematical, and political logos of the Gregorian model. Heidegger argues that to dwell means "to remain, to stay in a place" $(1971,144)$. "To dwell" implies the verb "to be" and "the way in which you are and I am, the manner in which we humans are on the earth [italics in original]" $(1971,145)$. To this effect, Heidegger links etymologically the Old English and High German word bauen - for building — to 'dwelling' and, more compellingly, to 'be' such that 'I am' signifies intrinsically 'I dwell'. More apposite to the vitality of seasonal being in place, bauen connotes "to cherish and protect, to preserve and care for, specifically to till the soil, to cultivate the vine" $(1971,145)$.

As integrated being, dwelling consists of the fourfold oneness of earth, sky, divinities, and mortals; each implies the other so that, for example, thinking of earth entails thinking of sky and divinities. For Heidegger, 'earth' refers to "blossoming and fruiting," whereas 'sky' connotes "the course of the changing moon...the year's seasons and their changes...the clemency and inclemency of the weather" $(1971,147)$. To dwell phenomenologically in the seasons is to leave "to the seasons their blessing and their inclemency" $(1971,148)$ - to apprehend the seasons without exerting predetermination, control, or constraint; to allow the seasons to "presence," in their originary places to the human sensorium in the act of seasontelling. Moreover, dwelling is "always a staying with things" $(1971,149)$. Heidegger points to the exigency of dwelling in the early twentieth century in which humanity "must ever learn to dwell [italics in original]" $(1971,159)$. In developing a "phenomenology of landscape," Tilley observes that, for Heidegger, "spaces open up by virtue of the dwelling of humanity or the staying with things that cannot be separated: the earth, the sky and the constellations, the divinities, birth and death [italics in original]" $(1994,13)$. Additionally, Tilley identifies the 
"total social fact of dwelling, serving to link place, praxis, cosmology and nurture" (1994, 13). The primacy of Heideggerian dwelling, in Tilley's analysis, implies the human body as the plenum of apprehension within the landscape and, by extension, within the seasons. Dwelling with and in the seasons is a habitus of being that reflects the integration of ontology, cosmology, plants, animals, insects, and human consciousness.

What does Heidegger mean by 'things' - a word which, in common parlance, tends to denote the inanimate stuff or commoditized objects of the world rather than the living beings calling forth the seasons in their sensuous natures? In the essay "The Thing," Heidegger differentiates between objects and things. An object is "that which stands before, over against, opposite us" $(1971,166)$ as the objectified "standing reserve" of technological enframement or Ge-stell (Heidegger 1977). In comparison to the instrumentally derived value of objects, a thing "stands forth" $(1971,166)$ agentically in its own right, manifesting the fourfold oneness of earth, sky, divinities, and mortals. "Thing" refers to the presencing of an essential nature of living and non-living entities $(1971,172)$. As the gathering of oneness, the thing entails the process of bringing forth Heidegger's notion of fourfold unity: "The thing stays - gathers and unites - the fourfold" $(1971,178)$. While they can be dead matter, things can also be animate, in Heidegger's view as "things, each thinging from time to time in its own way" $(1971,180)$. Hence, rethinking the Australian seasons means to dwell with things through the seasons in the places that circumscribe each: the cocky apples and the wild yams in Yawaru country north of Broome, Western Australia, or the banksia and red gums in Nyoongar country near Perth, for instance. The "thinging" of seasonal things is their presencing through their sensory manifestations - their ripening, effusions, stridulations - at particular times of the year. The human body, thus, is a sensing agent of the seasons in conjunction with knowledge of phenological details, such as those recorded by the IWKP, including flowering, fruiting, nesting, and moulting times, for example.

The concept of the human body as the plenum of sensory apprehension, while weak in Heidegger's account of the presencing of things, is more clearly emphasized in MerleauPonty's work, particularly Phenomenology of Perception. Part One, “The Body” (2012, 95205), outlines Merleau-Ponty’s corporeal phenomenology—a complex philosophical position drawing from psychology, which I will only describe briefly here in order to suggest a complementary conceptual perspective to 'the thing'. In comparable terms to Heidegger, Merleau-Ponty $(2012,61)$ avers that "sense experience is that vital communication with the world which makes it present as a familiar setting of our life." Sense experience is crucial to the presencing of things. Moreover, embodiment-living in one's senses and 
knowing/navigating the world sensuously through one's body - is a condition of "the temporal structure of being in the world" $(2012,86)$. Time is integral to the twin conditions of embodiment and being. Importantly, Merleau-Ponty's account of phenomenology attends to human sensation. As part of the plenum of apprehension, kinaesthetic sensations result from the movements of one's body in space (Merleau-Ponty 2012, 96). On the whole, Merleau-Ponty's concern is for the incarnate subject; his phenomenology counters the objectification - i.e., dissection, commoditization, marginalization - of the living body (Glendinning 2007, 134). Instead, the human body, rather than an object in the world, is the primary means through which we communicate with others and our environments (Glendinning 2007, 135).

Extending Heidegger and Merleau-Ponty, recent work in phenomenological geography and embodied cultural studies provides an additional conceptual foundation for a phenomenology of the seasons. Barbara Bender outlines a perspective on geographical research "where the time duration is measured in terms of human embodied experience of place and movement, of memory and expectation" $(2002,103)$. Bender implies that, in lieu of fixed points of reference for season-keeping, the human body acts as an ever-open sensorium, marking the seasons somatically in their fugue-like progression over time. Cultural theorist John Ryan terms this condition "embodied temporality" or the "sense for time and seasons engendered through physical, multisensorial interactions with place" (2012, "(De)colonising the Australian Seasons," para. 5). Ryan refers to Australian ethnobotanist Philip Clarke's work on Aboriginal "calendar plants" to describe seasonal things that provide-often simultaneously - a time-keeping measure and a source of physical sustenance. Similarly, Christopher Tilley argues that human embodiment—entailing multi-sensory openness to the things of the seasons-is essential to a phenomenology of place: "A phenomenologist's experience of landscape is one that takes place through the medium of his or her sensing and sensed carnal body" (Tilley 2010, 25), a characteristically Merleau-Pontian position. Extending Tilley's framework, a phenomenological approach to the seasons implies a "dialogic relationship between person and landscape" which stresses the materiality of landscapes as "real and physical rather than simply cognised or imagined" $(2010,26)$. In Heideggerian terms, the materiality of earth is the "blossoming and fruiting" - the ecological processes which underlie the presencing of things. For Tilley, a number of attributes and dispositions define phenomenological being in landscape, including "perception (seeing, hearing, touching), bodily actions and movements, and intentionality, emotion and awareness residing in systems of belief and decision-making, remembrance and evaluation" $(1994,12)$. 
All of these modes of experience and cognition are integral to a phenomenology of the seasons.

\section{Seasons of our inheritance: The appearance of the Gregorian model}

Turning from phenomenology for a moment, this section outlines the emergence of the twelve-month, four-season Gregorian calendar (also known as the Christian or Western calendar) from the Julian calendar of the ancient Romans. Why should Entwistle go through the trouble of redefining the Australian seasons? What's wrong with the four season scorethe venerable subject of much European and North American cultural reverie-in Australia? The aim of this section is to follow Entwistle's proposal to the origin of the four seasons and to argue that phenomenological, place-based awareness is not integral to the Western calendar that most of us use on a daily basis. In fact, the global transition to the Gregorian calendar took until the early 1900 s to reach completion. In 1582, the transition was instigated when the Gregorian calendar ("new style" (N.S.)), replaced the Julian calendar ("old style" (O.S.)) (Hawkins 1751). This erasure of an "extra" ten days - produced over time by the Julian system - corrected cumulative calendrical “shifts since Caesar" (Feeney 2007, 150). The Gregorian calendar is now the international civil calendar and derives from the $16^{\text {th }}$ century European desire to normalize Catholic and Protestant ceremonial dates (Doggett 1992, 580). In the Julian and Gregorian schemes, the four seasons - each approximately three months in duration - correspond to two equinoxes and two solstices per annum. Whereas land-based calendars must be experienced phenomenologically to be appreciated and often have fewer or greater than four seasons, the Gregorian model largely stems from structural, religious, political, and, later, colonial prerogatives.

The current use of the Gregorian calendar and associated four seasons in Australia can be traced to the British adoption of the calendar in 1752. Mathematically moderated, the Gregorian seasons are based on the solstices and equinoxes. Winter solstice is the shortest day, while summer solstice is the longest; the two equinoxes occur when night and day are of equal length. The Gregorian calendar - which is the underlying template for the four Western seasons - constitutes a grid-like temporal imposition on the seasonally diverse places comprising the Australian land mass. The institutionalization of the calendar is an aspect of the colonization of time-which belies the mismatch, at the core of Entwistle's call, between the diverse climates of Australian regions and the four-season overlay. 
The Gregorian calendar and its Julian precedent are structural devices for reckoning time. Anthony Aveni (1990) discerns between structural and ecological time in order to identify different modes of season-reckoning, as well as the colonizing intersection of Western and indigenous calendrical systems. Aveni (1990) defines ecological time as "temporal knowledge...determined by the individual as a participant in organized society" (174) which encompasses "events in the natural world that portend change" (176). Cyclical and integrative of culture and nature, eco-time foregrounds occurrences in the natural world: "The time marker - whether flood, worm, or stars - is recognized to have a seasonal cyclic rhythm independent of human action" (Aveni 1990, 176). Whereas eco-time relates "the response of human behavior to the cycles of nature" (Aveni 1990, 177), structural time prioritizes the rituals and behaviors that regulate societies (181). In other words, structural time is based on socially significant reference points-rituals and ceremonies, for example. For Aveni, indigenous calendars tend to integrate ecological and structural time-keeping, leading to nuanced modes of season-reckoning that are subjective, perceptual, fluid, and potentially variable from year to year.

The meaning and function of a calendar are linked to predictability and the control of time. Agnes Michels $(1967,9)$ defines a calendar as "a device for measuring time, by which [people] can plan for the future and keep a record of the past." Comparably, L.E. Doggett defines a calendar as "a system of organizing units of time for the purpose of reckoning time over extended periods...some calendars are codified in written laws [i.e. the Gregorian]; others are transmitted by oral tradition [i.e., the Nyoongar, traditionally]" (Doggett 1992, 575). Aveni $(1990,6)$ states that the underlying premise of a calendrical system is that a "temporal order" already exists in the natural world. A calendar merely identifies, exposes, and codifies this order. By establishing a structure for capturing and controlling the order, an institutionalized calendar avoids the problem of variation in seasonal durations in different places within a geography as vast as Australia. The problem of variation, according to structural thinking, is intrinsic to the subjective sensory reckoning of seasons, as evident in many Indigenous calendar systems (Aveni 1990, 6). In differentiating between structural time and ecological time, Aveni (1990, 123) emphasizes that the seasons overlap in reality; their edges are not hard and fast and do not strike firmly at certain calendrical nodes. This overlapping denotes "a sense of instability to the event sequences that make up the cycle of nature's behavior." Such instability in nature, however, for Michels (1967, 9-10), renders the (northern hemisphere) seasons an unsound basis of "only relative value" for a calendar: "although the seasons proceed in a regular sequence from year to year, they may vary 
considerably in length owing to variations in the weather." Moreover, to compound the difficulty of seasonal standardization and the need for a uniform system not derived from ecology, the "seasons also vary locally" (Michels 1967, 9-10) — which is certainly the landbased reality in Australia.

Four-season thinking is evident in the writings of the English Saint Bede (also known as the Venerable Bede, ca. AD 672-735). He connects the four seasons to the temperate conditions of the northern hemisphere and also to the four humors of the human body. For Bede, the seasons firstly derive from the English climate as the proper markers of the temporal order:

The seasons [tempora] take their name from this temperateness; or else they are rightly called tempora because they turn one into the other, being tempered one to another by some qualitative likeness. For winter is cold and wet, inasmuch as the Sun is quite far off; spring, when [the Sun] comes back above the Earth, is wet and warm; summer, when it waxes very hot, is warm and dry; autumn, when it falls to the lower regions, dry and cold. (Bede 1999, 100)

Bede $(1999,100-1)$ then characterizes the human body a "microcosm" and "a smaller universe" in which the four humors_-blood, black bile, red bile, phlegmatic humorscorrespond to the four seasons. Hence, certain humors manifest during certain seasons. The four qualities of hot, cold, wet, and dry-which couple to produce the conditions of the seasons - constitute the human humors as well. Bede associates qualities and humors with the seasons. While an embodied seasonal philosophy, Bede's thinking reiterates the quarterly division of the year implied in the ancient Roman term tempora annu or "times of year" (Holford-Strevens 2005, 80). Thus, Bede's humoral philosophy speaks of the generation of the four seasons in northern hemispherical climates and bodies.

In B.C.E. 46, Julius Caesar replaced the ten-month Roman lunar calendar with a twelve-month system (Fredregill 1970, 13). Caesar's schema, which became known as the Julian calendar, averaged 365.25 days per year (Fredregill 1970, 14). As the ancient precedent for the modern calendar, it comprised twelve months, although they were denoted by somewhat different names (e.g., Sextilis rather than August). The main liability of the Julian calendar - addressed by the Gregorian reform - was calendrical drift: the tropical year measured approximately 365.24219 mean solar days (Richards 1999, 239). Pointing to the discrepancy between Gregorian and Julian calendars, Fredregill $(1970,14)$ terms the Julian 
calendar "slow." In calculating slightly more days in the calendar year than the tropical year, the Julian system caused annual events to fall earlier in the calendar year at a rate of one day per 128 years (Richards 1999, 239). To its discredit, the average Julian annum comprised slightly too many days. Of temporal and religious concern, the actual vernal equinox began occurring in advance of its calendar date March 21, and astronomical new moons were reckoned earlier and earlier (Richards 1999, 352). Of particular concern for the medieval Church, calendrical drift caused Easter to fall on unsuitable days (Richards 1999, 249).

In A.D. February 1582, Pope Gregory XIII introduced the Gregorian calendar, instigating the Julian reformation by a bull known as Inter Gravissimas (Duncan 1999, 261289, Richards 1999, 239-256, Methuen 2008, 61-73, Willes 1700). In consultation with the astronomer Ignazio Danti (1536-86), Gregory became certain that the equinoxes were falling on incorrect days as a result of Julian drift (Richards 1999, 241). By A.D 1582, the accumulated error of the Julian drift tallied more than ten days. In an edict issued eight months before the calendar reform would be instituted, Pope Gregory XIII corrected the tenday error, mandating that October 15, 1582 revert to October 4, 1582. This reformation eliminated about ten days of Julian drift, accumulated over 1,600 years since the institution of Caesar's calendar (Duncan 1999, 261-262). Through this mandate, Gregory advanced the recommendations of the Council of Trent; although it was on the agenda of the Council, calendar reform was not sufficiently carried out until the papal decree (Richards 1999, 241).

Physician and astronomer Aluise Baldassar Lilio (1510-76) designed the Gregorian calendar for Pope Gregory (Richards 1999, 243). To correct the Julian drift, Lilio recommended that the first year of each century skip the leap year, except for years, such as 1600 and 2000, that could be divided evenly by 400 (Fredregill 1970, 14). The Gregorian reform mandated that the leap year occur every four years, but not during these particular years. It also included standards for calculating Easter, based on a revised table of new and full moons (Doggett 1992, 583, Richards 1999, 352), and assigned the beginning of spring to March 21 (Borst 1993, 103). Considering the calendar's relevance now, David Duncan (1999, 289) calls the Gregorian scheme "the world's calendar: a code for measuring time that today all but the most isolated peoples use as the global standard for measuring time." In comparable terms, E.G. Richards $(1999,256)$ comments that, following its introduction to Britain in 1752, "the Gregorian calendar was later taken to the four corners of the globe on the back of the British Empire. It is now all but universally used." In comparison to the Julian, the Gregorian system preserves three days every 400 years, allowing the activities of Western cultures to align almost uniformly with the solar year until A.D. 4000. 
Bonnie Blackburn and Leofranc Holford-Strevens $(1999,682)$ summarize, in The Oxford Companion to the Year, that the "adjustment was necessary because the Julian year, consisting of 365 days, with a $366^{\text {th }}$ day added every fourth year, has an average length of 365 days 6 hours, which is some 11 minutes 12 seconds too long, causing Julian dates to fall progressively further behind the sun.” However, the Gregorian schema was not instantly adopted by all Western countries. It took approximately 300 years to become the calendrical norm and was met with social, political, and religious resistance (Donaldson 1996b, 95). In England, the reform sparked controversy, as the opposition's oft-cited motto attests: "Give us back our eleven days.” A British Act of Parliament in 1752 introduced the Gregorian calendar or the "new style" (Richards 1999, 252-56). Britain's decision came 170 years after the rest of Europe, making it one of the last European countries to do so. The Act (24 Geo. II, ch. 23) was passed "for regulating the commencement of the year, and for correcting the calendar now in use" (quoted in Richards 1999, 253). Presented to Parliament by Lord Chesterfield, it became law on May 22, 1751 (Richards 1999, 253). Accordingly, 12 days were "eliminated" when September 14, 1752 reverted to September 2, 1752 (Feeney 2007, 151, 281, Duncan 1999, 277-78).

After its legalization in Britain, the Gregorian calendar was distributed to the colonies, including North America and, later, Australia. The standardization of season-reckoning in Australia culminated in the Meteorology Act of August 1906 and, subsequently, the creation of the Bureau of Meteorology in 1908 (Australian Bureau of Meteorology 2008a, 7). In 2012, the autumn equinox in Australia was March 20; the winter solstice, June 21; the spring equinox, September 23; and the summer solstice, December 21 (Australian Bureau of Meteorology 2013). However, rather than following the solstices and equinoxes in determining the start dates for seasons, Australia uses the international meteorological definition for the southern hemisphere. This mandates three-month "meteorological" or "calendrical" (rather than astronomical) seasons beginning the first of each month: September 1 (spring), December 1 (summer), March 1 (autumn), and June 1 (winter). The Australian convention makes the highly statistical process of record-keeping - as regulated by the Australian Bureau of Meteorology-more convenient and consistent.

Entwistle's initiative to rework the Australian seasons responds to the imperialist history of the Gregorian calendar and reflects his awareness of the indigenous calendars and endemic seasons of Australia that preceded colonization. However, his criticism of the four seasons down-under is not new. In the mid-1990s, Steve Symonds, a spokesperson for the Weather Bureau of New South Wales, commented bluntly that: 
We [settler society] are cultural imperialists and we have just said what we want the weather to be. We came out here and said that there are four seasons in Europe so four seasons there should be here. Why should there be four seasons in Australia just because there are four seasons in London? (quoted in Donaldson 1996a, 204)

As this section has detailed, the Gregorian calendar - applied to the immense landmass and cultural diversity of Australia - reiterates the processes of colonization and forever inscribes a history of religious conflict and ecological repression. The Western calendar disregards the ground of places and the materiality of things entangled with temporal awareness. In his analysis of Indigenous calendrical systems, the anthropologist Alfred Gell (1992, 313) avers that "the intertwining of calendars and power...extends to the processes of colonial subjugation." The importation of the four seasons to Australia—originating in the Julian drift, the Gregorian reform, and the dissemination of the calendar through British empire-posed the possibility of the crossing out of the endemic seasons of Aboriginal cultures. However, as the next section will highlight through a case study of the Nyoongar of the South-West region of Western Australia (WA), vibrant traditions of endemic seasonality endure, despite the impact of the colonial standard. Indigenous seasonal traditions are necessary counterpoints to any broadly applied, national seasonal paradigm — whether four or five.

\section{Seasons of the South-West: The endemic calendar of the Nyoongar}

Traditions of endemic seasonality — along with the cultural integrity underlying themshould not be overshadowed by national standards - revisionist or Gregorian. Like the Western calendar, seasonal calendars or "indigenous ecological calendars" are cultural constructs - "timetables that divide the year into seasons and describe expected conditions and resource availability" (Prober, O'Connor, and Walsh 2011,2). Yet, a land-based seasonal calendar, unlike the Western calendar, is intrinsically connected to the ground - the ecology and culture of a place, and the corporeal things of nature which announce the seasons (Usher 2000). In contrast to the four-season Western regime, "indigenous calendars," as Tim Entwistle concedes in Australian Geographic, more appropriately reflect regional Australian climates than the globalized four-season schema formulated in Europe. Australian indigenous calendars offer the vital complement to Entwistle's revised calendar. Aboriginal cultures have unique place-based systems of season-keeping, recognizing two, four, six, seven, and nine 
seasons, for example (Clarke 2007, 54-59). The danger of Entwistle's proposal is that his new model, with its relatively minor reorientation toward native plants, will simply substitute in for the Gregorian scheme - the complex nuances of each indigenous calendar again rendered one-dimensional by the imposition of a "fixed system of reference" over the entire country (Prober, O'Connor, and Walsh 2011, 2).

Derived from European political, religious, and climatic circumstances, the Gregorian calendar is an apparatus of colonization that has been misapplied in Australia and "staunchly retained" since the 1800s (Clarke 2007, 54). In contrast, the endemic calendars of Australian Aboriginal people offer pathways to ecological time-foregrounding events in the natural world — and structural time — relating the seasons to events of social significance, including ceremonies and festivals. The Nyoongar calendar of the South-West is a living system of time-keeping that implies phenomenological engagement with the environment. Here, the presencing of the things of nature — wind, temperature, fire, flora, fauna — signifies the seasons.

This section begins with historical interpretations of the six Nyoongar seasons, recorded by Western Australian settlers and colonists, then shifts to contemporary explanations of the traditional seasons by Nyoongar elders and teachers. In proposing "embodied temporality" through his analysis of the Nyoongar seasons, Ryan (2012a) interrogates historical sources, including the diaries of Albany-based doctor and settler Scott Nind (1831/1979), lawyer and farmer George Fletcher Moore (1884/1978), and early twentieth-century ethnographer and journalist Daisy Bates (1985). Extending Ryan's initial historical investigations, this section will introduce material from George Fletcher Moore's diaries, as well as extracts from the published journals of the Benedictine monk Dom Rosendo Salvado and statements from colonial Western Australian newspaper articles referring to the Nyoongar seasons.

In Aboriginal Australia, according to Clarke (2007, 54), totemic associations, burning regimes, celestial movements, animal behaviors, wind patterns, temperature shifts, flowering phases, and rainfall levels together announce the arrival of each season. Instead of the measuring of time that is intrinsic to the Gregorian calendar, Aboriginal peoples apprehend environmental changes corporeally in order to mark the movement of the seasons (Clarke 2009, 94). Unlike the Western calendar, Australian "bush calendars" have between two and nine divisions, and the duration of each season varies annually (Clarke 2009, 95). Prior to European settlement, Nyoongar people gathered plant foods and hunted animals according to a six-season calendar, with whole camps moving into areas when particular foods became 
harvestable (Nannup and Deeley 2006, Rusack et al. 2011, Stasiuk and Sillifant 2005, Tilbrook 1983, 3). In Albany, oral histories describe the local Nyoongar tradition of movement with the seasons from the coast in the summer to the inland in the winter (Tilbrook 1983, 145). Traditional Nyoongar seasonal awareness "comprises organized artisanal knowledge gained through observation and adjustment over timeframes of thousands of years, often strongly linked with an ontology such as that shaped by the 'Dreaming"' (Prober, O'Connor, and Walsh 2011,2).

Drawing from historical sources, including key records written by Bates, Nind, and Moore, Neville Green (1984, 10-11) provides a summary of the six Nyoongar seasons and their differing orthographies in Perth and Albany, Western Australia. In Perth, about 250 miles northwest of Albany, Birok is comparable to early summer (the first summer) and comprises December and January; in Albany, the season is known as Meerningal. Burnoru is the Nyoongar late summer (the second summer) and comprises February and March; in Albany, known as Maungernan. Geran includes the autumn months of April and May; known as Beruc to Albany Nyoongar people. Maggoro includes the winter months of June and July; known as Meertilluc in Albany. Jilba refers to the spring months of August and September; Pourner in Albany. Finally, Kambarang encompasses the spring months of October and November; denoted as Mokkar in Albany. The six seasons are made palpable through the presencing of different natural things - "roots, birds, eggs, edible grubs, lizards" (Green 1984, 10-11), registered multi-sensorially by individuals through their powers of sight, touch, taste, smell, and sound.

The Benedictine monk, Dom Rosendo Salvado (1814-1900), who established the New Norcia monastery on the banks of the Moore River north of Perth, commented that "it seems that some natives divide the year into six different seasons; but many others divide it into four, which they call cielba [jilba], mocur, ponar, piroc, that is, autumn, winter, spring, and summer. The months are distinguished from one another by the moon, but they are not given individual names, or divided into weeks. Again the days are not distinguished except by the position of the moon" (Salvado 1977, 131). Curiously, Salvado only references four of six Albany seasons, Jilba (cielba), Mokkar (mocur), Pourner (ponar), and Birok (piroc), despite the existing account of colonial doctor Isaac Scott Nind (1797-1868), published in 1831. Nind $(1831 / 1979,35)$ notes that "the greatest assemblages [of Albany area Nyoongar people] are in the autumn (pourner), when fish are to be procured in the greatest abundance." He observed six seasons "beginning with June and July, or Winter: Mawkur, Meerningal, Maungernan, Beruc, Meertilluc, and Pourer" [italics added] (Nind 1831/1979, 54). Salvado's 
emphasis on the four Nyoongar seasons might reflect an intractable four-season logos that simply could not rationalize in-between states of temporality for, as he says, "it seems that some natives divide the year into six different seasons [italics added].” Moreover, Salvado noted that Nyoongars reckoned weeks and days according to the moon, but that these smaller divisions of time were not as important as the six seasons in the Nyoongar temporal order.

In contrast to the Nyoongar bush calendar, as the previous section demonstrated, the Gregorian calendar pivots on the precise calculation of time in determining the four seasons and the exact placement of Christian holy days. In his discussion of Aboriginal temporality, Mike Donaldson (1996a, 193) describes a non-Western sense of time as "enveloping. Both cyclical and circular, it accorded with the need for seasonal movement, the aggregation and disaggregation of groups." "Nyoongar time," for Donaldson (1996a, 200-1), reflects "close ties with the land... which blurred the distinctions between work and leisure." Based on this temporal sense, Nyoongar seasons reflect natural events and are connected to the procurement of food and movements of communities - thereby bridging ecological and structural time. Salvado $(1977,289)$ observed "it is worth noting that the Australian natives...use the title 'grass season' of the period in which the new grass is born and the buds open, that is, the months corresponding to April-May of the northern hemisphere (our months, however, being autumn for them)." In the Perth-area Nyoongar calendar, the months of April and May correspond to Geran, signified by the presencing of grass buds and associated flora and fauna. The budding of grass is an important ecological phenomenon in the annual cycle of the kwongan sand plain ecosystem fringing Salvado's New Norcia settlement to the west. Salvado's statements suggest that Geran is a shifting denominator-a movable category of time - that depends on a variety of biotic, abiotic, astronomical, and cultural factors, rather than the pre-set calendrical months of April or May, turning in a predetermined fashion on the first and last days of their cycles.

As embodied temporality (Ryan's preferred term used here to encompass ecological and structural time), the seasons governed traditional Nyoongar movements, activities, and customs. An article in an 1833 edition of The Perth Gazette noted that a reconciliatory meeting between warring settlers and Nyoongars "could not be effected at present, as the tribes were so much dispursed [sic], and not until the yellow season (the bloom of the Banksia,) in December, January, and February. At this time the country is generally fired [italics in original]" (The Perth Gazette 1833, 142). The three months listed in the article correspond to Birok and Burnoru when different species of banksia bloom, including the bull banksia (mangite or Banksia grandis) — the flowers producing an abundance of nectar, which 
was steeped in water or sucked directly by Aboriginal peoples. During the yellow season, the Christmas tree (Nuytsia floribunda), known as mudja - the Nyoongar word for fire (Ryan 2012b) - also blossomed. Further to the color symbology of the seasons, it was during Birok and Burnoru that Nyoongars set fires to encourage grazing animals and the regrowth of food plants (Hallam 1975). However, banksia nectar-as a sensuous thing announcing the seasons phenomenologically — was also important during other times of year. Writing in October 1833, George Fletcher Moore $(2006,292)$ reported that "this is the season now for young parrots. I am told that the natives suck the honey out of their bills which the mother has just fed them with from the Banksia flowers." During the season of Kambarang, Nyoongars hunted young birds and eggs (Elkin 1943, 36). Additionally, Moore (2006, 315) from March 1834 observed that Nyoongars "pull the blossoms of the red gum tree (now in flower), steep them in water, and drink the water, which acquires a taste like sugar and water by this process." Between Burnoru and Makaru, the red gum tree (marri or Corymbia calophylla) flowers throughout the South-West region.

As suggested by the term "the yellow season," some contemporary explanations of the Nyoongar seasons point to color typologies with phenomenological bearing on human perception of the temporal world. However, these typologies are not always consistent between sources. Our Place Newsletter (Kurongkurl Katitjin Centre 2011, 5) notes that colors are used to teach seasonal knowledge and to help Nyoongar people identify "the correct time of year" for certain activities. Birok is associated with the color red or mirda, symbolizing heat, fire, and the sun. Burnoru is signified by the color orange or yoornt mirda, representing the profusion of fish and lack of rain characteristic of this season. Geran's color is green, or nodjam, correlating to the return of cooler weather and the light green appearance of eucalypt trees. Maggoro is blue, or wooyan, with dark blue, specifically signifying the onset of rain and cold temperatures. Jilba is associated with the color pink, or mirda mokiny, with pink or purple indicating the proliferation of wildflowers in the South-West during this season. Finally, Kambarang (not Birok and Burnoru, as indicated above) is linked to the color yellow, or yoornt, symbolizing the arrival of hot weather and other "yellow" events that complete the yearly cycle (Kurongkurl Katitjin Centre 2011, 5).

As a contemporary teacher of Nyoongar seasonal knowledge, Len Collard, a Traditional Owner of the Whadjuck or Perth metropolitan area Nyoongar, comments that "we utilize six seasons of the year for food and sustenance, and never damage or kill our resources unnecessarily. The land is our mother and our nurturer and our guiding light" (Stasiuk and Sillifant 2005). Collard links the six Nyoongar seasons to meteorological conditions 
(ecological time), such as wind directions and temperatures, but also to the procurement of food, maintenance of cultural knowledge, and performance of ceremonies (structural time):

The Nyoongar seasons are Bunuru with hot easterly and north winds...Djeran becomes cooler with wind from the south-west...Makuru, cold and wet with westerly gales...Djilba, becoming warmer...Kambarang, rain decreasing...Birak, hot and dry with easterly winds during the day and south-west sea breezes in the afternoon...There were between 30 and 40 distinct roots, nuts, and vegetables eaten by Nyoongar, which are gathered nearly all-year round...There was hardly any shortage of food throughout the six season cycle with katitjin or knowledge given to the Nyoongar by the Waagal [Creation Serpent] to manage our land according to the seasons. (Collard in Stasiuk and Sillifant 2005)

Hence, for Collard, the endemic six seasons of the Nyoongar derive uniquely from the meteorological, botanical, and cultural contexts of the South-West Australian landmass. Such variables factoring into the Nyoongar bush calendar coalesce to signify the onset of each of the seasons. Crucially, however, the physical openness of humans to the sensuous nuances of experience is the mode through which the things of the South-West-red gums, banksias, the wind, roots, nuts, vegetables, nectar, birds - announce themselves. This phenomenological mode of gaining seasonal knowledge shifts, not only from season to season, but from region to region. Thus, a phenomenology of the seasons engages people and the things of nature in their milieux of dwelling, leading to place-based and embodied temporality.

\section{Seasons of our dwelling: The Indigenous Weather Knowledge Project (IWKP)}

In December 2012, Edith Cowan University and the Bureau of Meteorology launched the Nyoongar weather calendar as part of the Indigenous Weather Knowledge Project's continuing effort to preserve and promote traditional Australian Aboriginal seasonal knowledge (Edith Cowan University 2012). The online calendar lists the six Nyoongar seasons as Birak, Bunuru, Djeran, Makuru, Djilba, and Kambarang (Australian Bureau of Meteorology 2012a). (See http://www.bom.gov.au/iwk/). As an educational and heritagebased tool, the IWKP website emphasizes that human perception is fundamental to understanding the endemic South-West seasons: "the Nyoongar seasons can be long or short and are indicated by what is happening and changing around us rather than by dates on a 
calendar" (Australian Bureau of Meteorology 2012a). For example, Birak (DecemberJanuary), the first summer or the season of the young, is marked by the easing of rain, the onset of warm weather, sea breezes from the southwest, easterly winds, fledgling birds, reptiles shedding their skin, and baby frogs. Bunuru (February-March), the second summer or season of adolescence, is signified by high heat and little rain, hot easterly winds, the white flowers of jarrah, marri, and ghost gums, and the bright red cones of female zamia (Macrozamia riedlei). Djeran (April-May), the ant season or season of adulthood, features the breaking of hot weather, cooler nights, light breezes from the south-east or south-west, flying ants, the red flowers of Corymbia ficifolia and Beaufortia aestiva, and the flowering of other banksias. Traditionally, during Djeran, Nyoongars consumed zamia nuts that were, earlier in the year, stored underground or water to hasten the food crop's detoxification. Shelters known as mia-mias were repaired in preparation for the coming cold season.

In addition to the Nyoongar calendar, the IWKP outlines the endemic seasonal knowledge of eight other Aboriginal cultures: Brambuk, D'harawal, Walabunnba, Yanyuwa, Jawoyn, Miriwoong, Wardaman, and Yawaru. For example, in the Yawaru calendar situated north of Broome, Western Australia, uses ecological indicators, such as the ripening of the cocky apple and the availability of wild yams, to indicate Mankala or the wet season (Australian Bureau of Meteorology 2012a). The Walabunnba people, living approximately $300 \mathrm{~km}$ north of Alice Springs in central Australia, recognize two seasons: Wantangka (the hot weather) and Yurluurrp (the cold weather). During Wantangka, the sweet bush plum is eaten when the fruit turns dark, and special "hot weather" ceremonies are performed during the season.

The IWKP website is the outcome of a collaboration between Indigenous Australian communities, the Aboriginal and Torres Strait Islander Commission (ATSIC), the Bureau of Meteorology, and Monash University's Centre for Australian Indigenous Studies (CAIS) and School of Geography and Environmental Science. The South West Aboriginal Land and Sea Council granted permission to the IWKP to display culturally sensitive Nyoongar seasonal information. Moreover, the IWKP is integral to the Bureau of Meteorology's Reconciliation Action Plan 2012-2015. One of the plan's objectives is "to liaise with community elders to expand traditional knowledge of weather and climate through seasonal calendar information" (Australian Bureau of Meteorology 2012b, 2). Indeed, as one of the original promulgators of the Western seasons in Australia, the Bureau of Meteorology concedes that "the four seasons we've adopted are not entirely appropriate for all regions of Australia." The Bureau praises "natural calendars" or "bush calendars" for reckoning the "natural seasons" according to 
ecological phenomena, such as "fruits, blossoms, insects, animals, as well as the temperature and whether it was a wet time of year" (Australian Bureau of Meteorology 2008b, 10).

In foregrounding ecocultural (environmental and cultural) waymarks which herald the passage of time, such as the ripening of the bush plum, the IWKP offers a phenological tool for appreciating the Aboriginal Australian seasons. The word 'phenology' stems from the Latin 'phaeno' and the Greek 'phaino'. 'Phenology' and 'phenomenon' share a common etymological root in the Greek 'phainein' for "to show" (Harper 2012), from which the words 'phantasm' and 'phenotype' come. Introduced in an 1853 article by Belgian botanist Charles Morren (1807-1858) and advanced in the 1880s by the Austrian botanist Karl Fritsch (18641934), phenology can be defined as "the study of periodic biological events in the animal and plant world as influenced by the environment, especially temperature changes driven by the environment" (Schwartz 2003, 3). For Morren, 'phenology' meant "to show, to appear: the science of phenomena that appear successively on the globe" (Keatley and Hudson 2010, 1). The first published English definition of phenology, following the term's adoption by the Council of the Meteorological Society in 1875, read "the observation of the first flowering and fruiting of plants, the foliation and defoliation of trees, the arrival, nesting, and departure of birds, and such like" (Anon. 1884 quoted in Keatley and Hudson 2010, 1). Further along, a 1972 American committee on phenology employed the following definition: "the study of the timing of recurring biological events" (Leith quoted in Keatley and Hudson 2010, 2).

Forwarded by the Bureau of Meteorology, the IWKP intersects with scientific knowledge of weather and the seasons. The project also highlights the seasonal heterogeneity of Australia. As an online resource containing an emergent collection of phenological information about Australian endemic seasons, the IWKP provides catalogue-like indications of the first occurrences of ecocultural events in the respective regions of the nine Aboriginal societies featured. However, immediate experience through the senses - of the endemic things of Australian places, including bush plums, zamia nuts, and wild yams-is indispensable to comprehending the seasons in their sensuous presencing. The phenomena that indicate seasonal passage — archived by the IWKP in consultation with elders - are integral to the habitus of people in a place. In a scientific sense, a phenology functions, in part, like a compendium of events. In contrast, a phenology of the Australian seasons, thus, integrates biotic, abiotic, cultural, cosmological, ceremonial, ontological, and corporeal aspects - all essential to Aboriginal temporal orders. Fostered through a phenomenological foundation, immediate embodied knowledge of the seasons is a much-needed complement to the largely cognitive, visual, and events-based perception of temporality. For example, 
although the bush plum flowers in summer, if I have never seen, tasted, or smelled its fruit, my knowledge of the endemic seasons of where I live will be limited-I must engage with the things of the seasons through which events manifest. Hence, endemic seasonalitywhether Mankaru of the Yawaru calendar or Djeran of the Nyoongar calendar-is intimate with embodied temporality, the recognition of time's passing through corporeal involvement with one's place. The IWKP offers a groundwork for phenomenological exploration of the seasons. Nevertheless, the information preserved and promoted by the IWKP should not be regarded as a substitute for immediate, real-time encounter with seasonal things- - but rather as a fact-based catalyst to such encounters.

Although an incomplete digital guide, the IWKP offers an accessible template for engaging with the Australian seasons through sensory experience. In analyzing the IWKP in these terms, I have distinguished between a phenology of the seasons - as cognitive recognition of temporal events - and a phenomenology of the seasons - as embodied, immanent interaction with the seasonal things that herald such events. Ultimately, a phenomenology complements a phenology of the seasons, encapsulated by the IWKP. Returning to Entwistle's proposal, even the more considered kinds of seasonal paradigms risk imposing a managerialist grid on the plural landscapes — bioregions, places, locales — that comprise Australia as a highly diverse ecocultural whole. For instance, in the five-season scheme, spring as a temporal denomination is entwined with the flowering of native plants. Although botanically sensitive, this prioritization backgrounds the other physiological events in the annual cycles of flora-as well as the cultural, sensorial, spiritual, ethnozoological, astronomical, and climatic considerations that collectively signify the seasons (Clarke 2009). Ecological and structural time lived out in place synergetically become embodied temporality. Flowering phases reflect one aspect of an endemic (land-based or Indigenous) calendar as an environmentally and culturally integrated whole. Through the fusion of phenomenological (experiential, sensory, place-based, actual) and phenological (cognitive, visual, enumerative, digital) approaches, the endemic seasons of Australia can be appreciated in their depth and extent.

\section{Conclusion: Living with seasonal diversity in Australia}

As suggested by Entwistle's call, Australia has an uneasy relationship to the four seasons of the Western calendar and the northern hemisphere. The rethinking of the Australian seasons entails the recognition of a multiplicity of seasons, calendars, cultures, and places. National 
models - whether the Gregorian four seasons or Entwistle's proposal for five seasons - can co-exist dynamically with robust traditions of endemic seasonality, exemplified by the Nyoongar six seasons and the Indigenous Weather Knowledge Project. As Clarke $(2009,101)$ comments, "while increasing globalization prevents European Australians from rejecting the European-derived calendar in favour of a plethora of regional calendars, the future investigation of indigenous seasonal knowledge and behaviour offers to help develop more relevant approaches to landscape management." As I have argued in this article, the "future investigation" of Indigenous calendars will need to be experiential, sensory, and place-based.

Hence, a dialogic perspective on the seasons is phenomenological and phenologicalcognitive and bodily - thus comprising the proposed portmanteau 'phen(omen)ology'. Attending to the seasonal things of place which pronounce the passage of time, a phen(omen)ology is a reflexive perspective on the seasons that blurs the distinction between intellection and embodiment. Moreover, a phen(omen)ology recognizes that actual seasonal boundaries vary year to year and from place to place according to an array of ecocultural factors. As Heidegger acknowledged, "a boundary is not that at which something stops but, as the Greeks recognized, the boundary is that from which something begins its presencing [italics in original]" $(1971,152)$. Learning to be with the presencing of seasonal things requires knowledge of when things tend to happen coupled to immediate sensory witnessing of their manifestation. 


\section{References}

Australian Bureau of Meteorology. 2008a. A century of science and service: The Australian Bureau of Meteorology 1908-2008. Melbourne, Australia: Bureau of Meteorology.

Australian Bureau of Meteorology. 2008b. Climate of Australia. Melbourne, Australia: Bureau of Meteorology.

Australian Bureau of Meteorology. 2012a. Indigenous weather knowledge. http://www.bom.gov.au/iwk/. Date of access: January 21, 2013.

Australian Bureau of Meteorology. 2012b. Reconciliation action plan 2012-2015. Melbourne, Australia: Bureau of Meteorology.

Australian Bureau of Meteorology. 2013. Australian weather calendar. http://www.bom.gov.au/calendar/annual/seasons.shtml. Date of access: January 28, 2013.

Aveni, Anthony. 1990. Empires of time: Calendars, clocks, and cultures. London, England: I.B. Tauris.

Bates, Daisy. 1985. The native tribes of Western Australia. Ed. Isobel White. Canberra, Australia: National Library of Australia.

Bede. 1999. Bede: The reckoning of time. Trans. Faith Wallis. Liverpool, England: Liverpool University Press.

Bender, Barbara. 2002. Time and landscape. Current Anthropology 43 (S4): 103-112.

Bindon, Peter, and Trevor Walley. 1992. Hunters and gatherers. Landscope 8, no. 1: 28-35.

Blackburn, Bonnie, and Leofranc Holford-Strevens. 1999. The Oxford companion to the year: An exploration of calendar customs and time-reckoning. Oxford, England: Oxford University Press.

Borst, Arno. 1993. The ordering of time: From the ancient computus to the modern computer. Cambridge, England: Polity Press.

Clarke, Philip. 2007. Aboriginal people and their plants. Dural Delivery Centre, Australia: Rosenberg.

Clarke, Philip. 2009. Australian Aboriginal ethnometeorology and seasonal calendars. History and Anthropology 20, no. 2: 79-106.

CSIRO. 2012. Indigenous seasonal indicators and climate change. www.csiro.au/Organisation-Structure/Divisions/Ecosystem-Sciences/Ngadju.aspx. Date of access: December 17, 2012. 
Doggett, L.E. 1992. Calendars. In Explanatory supplement to the astronomical almanac. Ed. P. Kenneth Seidelmann, 575-608. Mill Valley, CA: University Science Books.

Donaldson, Mike. 1996a. The End of Time?: Aboriginal temporality and the British invasion of Australia. Time \& Society 5, no. 2: 187-207.

Donaldson, Mike. 1996b. Taking our time: Remaking the temporal order. Nedlands, Australia: University of Western Australia Press.

Duncan, David Ewing. 1999. Calendar: Humanity's epic struggle to determine a true and accurate year. New York, NY: Avon Books.

Duncan, Katie. 2011. Sprinting into sprummer. In Australian Geographic, Apr. 1, 2011. Academic OneFile. Date of access: January 15, 2013.

Edith Cowan University. 2013. ECU and BOM launch Nyoongar weather calendar. http://www.ecu.edu.au/news/latest-news/2012/12/ecu-and-bom-launch-nyoongarweather-calendar. Date of access: February 15, 2013.

Elkin, Adolphus Peter. 1943. The Australian Aborigines: How to understand them. Sydney, Australia: Angus \& Robertson.

Feeney, Denis. 2007. Caesar's calendar: Ancient time and the beginnings of history. Berkeley, CA: University of California Press.

Fredregill, Ernest. 1970. 1000 years: A Julian/Gregorian perpetual calendar, A.D. 1100 to A.D. 2099. New York, NY: Exposition Press.

Gell, Alfred. 1992. The anthropology of time: Cultural constructions of temporal maps and images. Oxford, England: Berg.

Glendinning, Simon. 2007. In the name of phenomenology. London, England: Routledge.

Green, Neville. 1984. Broken spears: Aborigines and Europeans in the Southwest of Australia. Cottesloe, Australia: Focus Education Services.

Hallam, S J. 1975. Fire and hearth: A study of Aboriginal usage and European usurpation in South-Western Australia. Canberra, Australia: Australian Institute of Aboriginal Studies.

Harper, Douglas. 2013. phenology (n.). http://www.etymonline.com/index.php?term=phenology. Date of access: February 5, 2013.

Hawkins, Aaron. 1751. The Gregorian and Julian calendars, or, The new and old stiles, arithmetically explained. London, England: M. Cooper. Making of the Modern World. http://find.galegroup.com/mome/infomark.do?\&source=gale\&prodId=MOME\&userG roupName=uwa\&tabID=T001\&docId=U3600934148\&type=multipage \&contentSet $=$ 
MOMEArticles\&version=1.0\&docLevel=FASCIMILE. Date of access January 29, 2013.

Heidegger, Martin. 1971. Poetry, language, thought. Trans. Albert Hofstadter. New York, NY: Harper Perennial.

Heidegger, Martin. 1977. The question concerning technology. In Martin Heidegger: Basic writings. Ed. D. Krell, 284-317. New York, NY: Harper \& Row.

Holford-Strevens, Leofranc. 2005. History of time: A very short introduction. Oxford, England: Oxford University Press.

Keatley, Marie, and Irene Hudson. 2010. Introduction and overview. In Phenological research: Methods for environmental and climate change analysis. Eds. Marie Keatley and Irene Hudson, 1-22. Dordrecht, The Netherlands: Springer.

Kurongkurl Katitjin Centre. 2011. Wongi Nyoongar - Talking Nyoongar. Our place: Official newsletter of Kurongkurl Katitjin Centre for Indigenous Australian Education and Research. Makaru Edition (Jun/Jul): 5. http://www.ecu.edu.au/_data/assets/pdf_file/0011/249293/Our-PlaceNewsletter_Makuru-11-Edition_WEB.pdf. Date of access: January 21, 2013. Merleau-Ponty, Maurice. 2012. Phenomenology of perception. Trans. Colin Smith. New York, NY: Routledge.

Methuen, Charlotte. 2008. Science and theology in the Reformation: Studies in theological interpretation and astronomical observation in sixteenth-century Germany. London, England: T \& T Clarke.

Michels, Agnes Kirsopp. 1967. The calendar of the Roman republic. Princeton, NJ: Princeton University Press.

Moore, George Fletcher. 1884/1978. Diary of ten years eventful life of an early settler in Western Australia and also A descriptive vocabulary of the language of the Aborigines. Nedlands, WA: University of Western Australia Press.

Moore, George Fletcher. 2006. The Millendon memoirs: George Fletcher Moore's Western Australian diaries and letters, 1830-1841. Ed. J.M.R. Cameron. Carlisle, Australia: Hesperian Press.

Nannup, Noel, and David Deeley. 2006. Rainfall and water as cultural drivers. In $1 s t$ National Hydropolis Conference. Perth, Australia.: Stormwater Industry Association. Nind, Scott. 1831/1979. Description of the Natives of King George's Sound (Swan River Colony) and adjoining country. In Nyungar, the people: Aboriginal customs in the 
southwest of Australia. Ed. Neville Green, 14- 55. North Perth, Australia.: Creative Research in association with Mt. Lawley College.

Prober, Suzanne, Michael O'Connor, and Fiona Walsh. 2011. Australian Aboriginal peoples' seasonal knowledges: A potential basis for shared understanding in environmental management. Ecology and Society 16, no. 2: 1- 16. http://www.ecologyandsociety.org/vol16/iss2/art12/. Date of access: January 21, 2013.

Richards, E.G. 1999. Mapping time: The calendar and its history. Oxford, England: Oxford University Press.

Rusack, Eleanor May, Joe Dortch, Ken Hayward, Michael Renton, Mathias Boer, and Pauline Grierson. 2011. The role of habitus in the maintenance of traditional Noongar plant knowledge in Southwest Western Australia. Human Ecology 39, no. 5: 673- 682.

Ryan, John. 2012a. The six seasons: Shifting Australian nature writing towards ecological time and embodied temporality. Transformations no. 21. http://www.transformationsjournal.org/journal/issue_21/article_01.shtml. Date of access: January 21, 2013.

Ryan, John. 2012b. Towards intimate relations: Gesture and contact between plants and people. PAN: Philosophy Activism Nature no. 9: 29-36.

Salvado, Dom Rosendo 1977. The Salvado memoirs: Historical memoirs of Australia and particularly of the Benedictine mission of New Norcia and of the habits and customs of the Australian natives. Trans. E.J. Stormon. Nedlands, Australia: University of Western Australia Press. Original edition, 1853.

Schwartz, Mark. 2003. Introduction. In Phenology: An integrative environmental science. Ed. Mark Schwartz, 3-8. Dordrecht, The Netherlands: Kluwer Academic Publishers.

South West Aboriginal Land \& Sea Council. 2009. 'It's still in my heart, this is my country': The single Noongar claim history. Nedlands, Australia: University of Western Australia Press.

Stasiuk, Glen, and Ash Sillifant (Directors). 2005. Noongar of the Beelier or Swan River. Prod. Glen Stasiuk. 20 mins., 28 secs. Murdoch, Australia: Kulbardi Productions. Steffen, Will, Andrew Burbidge, Lesley Hughes, Roger Kitching, David Lindenmayer, Warren Musgrave, Mark Stafford Smith, and Patricia A. Werner. 2009. Australia's biodiversity and climate change. Collingwood, Australia: CSIRO Publishing.

The Perth Gazette. 1833. The Natives: Interesting interview. In The Perth Gazette and Western Australian Journal (WA: 1833-1847), Sept. 7, 1833. National Library of 
Australia Trove. http://nla.gov.au/nla.news-article641889. Date of access: January 21, 2013.

Tilbrook, Lois. 1983. Nyungar tradition: Glimpses of Aborigines of South-Western Australia 1829-1914. Nedlands, Australia: University of Western Australia Press.

Tilley, Christopher. 1994. A phenomenology of landscape: Places, paths and monuments. Oxford, England: Berg.

Tilley, Christopher. 2010. Outline of a phenomenological perspective. In Interpreting landscapes: Geologies, topographies, identities, 25-40. Walnut Creek, CA: Left Coast Press.

Usher, P. 2000. Traditional ecological knowledge in environmental assessment and management. Arctic. 53, no. 2: 183-193.

Van den Berg, Rosemary. 2002. Nyoongar people of Australia: Perspectives on racism and multiculturalism. Leiden, The Netherlands: Brill.

Willes, John. 1700. The Julian and Gregorian year, or, The difference betwixt the old and new-stile. London, England: Richard Sare. Early English Books Online. http://eebo.chadwyck.com/home. Date of access: January 29, 2013. 